DR. CHANDRASHEKHAR A KUBAL (Orcid ID : 0000-0003-4043-2943)

Article type : Original

\title{
Pre-Liver Transplant Cardiac Catheterization is Associated with Low Rate of Myocardial Infarction and Cardiac Mortality
}

*Issa Kutkut, MD; * Rayan Jo Rachwan, MD²; Lava R. Timsina, PhD; Marwan S. Ghabril, MD; Marco A. Lacerda, MD4; Chandrashekhar A. Kubal, MD, PhD5; Patrick D. Bourdillon, MD ${ }^{6}$ and Richard S. Mangus, MD

${ }^{1}$ Division of Cardiology, NewYork-Presbyterian Brooklyn Methodist Hospital, Brooklyn, New York.

${ }^{2}$ Department of Internal Medicine; ${ }^{3}$ Department of Surgery; ${ }^{4}$ Division of Gastroenterology and Hepatology, Department of Internal Medicine; ${ }^{5}$ Department of Transplantation Surgery; and ${ }^{6}$ Division of Cardiology, Department of Internal Medicine, Indiana University School of Medicine, Indianapolis, Indiana

*Issa Kutkut and Rayan Jo Rachwan contributed equally as co-first authors.

Running head: Cardiac Catheterization in Liver Transplant

Total word count: 5,966

Keywords: preoperative evaluation; coronary artery disease; coronary angiography; cirrhosis; liver transplantation.

This is the author's manuscript of the article published in final edited form as:

Kutkut, I., Rachwan, R. J., Timsina, L. R., Ghabril, M. S., Lacerda, M. A., Kubal, C. A., ... Mangus, R. S. (2019). Pre-Liver Transplant Cardiac Catheterization is Associated with Low Rate of Myocardial Infarction and Cardiac Mortality. Hepatology. https://doi.org/10.1002/hep.31023 


\section{Abbreviations:}

CAD: coronary artery disease

CATH: cardiac catheterization

CCTA: coronary computed tomography angiography

EKG: electrocardiogram

$\mathrm{LT}$ : liver transplant

MI: myocardial infarction

$\mathrm{PCl}$ : percutaneous coronary intervention

SE: stress echocardiogram

WMA: wall motion abnormalities

Grants and financial support: nothing to declare.

Acknowledgement: the authors would like to thank Ricardo V. Tuason, Senior Clinical Business Analyst at Indiana University Health, for his assistance with data collection.

\section{Corresponding author:}

Richard S. Mangus, MD MS FACS

550 North University Blvd, Room 4601, Indianapolis, Indiana, 46202, USA

Phone and Fax: (317)919-6734

E-mail: rmangus@iupui.edu

This article is protected by copyright. All rights reserved 


\section{Abstract}

Background: A previous study at Indiana University demonstrated a reduction in myocardial infarction (MI) incidence with increased frequency of cardiac catheterization (CATH) in liver transplant (LT) candidates. A strict protocol for performing CATH based upon predefined risk factors, rather than non-invasive testing alone, was applied to a subgroup (2009-2010) from that study. CATH was followed by percutaneous coronary intervention ( $\mathrm{PCl}$ ) in cases of significant coronary artery disease (CAD; $\geq 50 \%$ stenosis). The current study applies this screening protocol to a larger cohort (2010-2016) to assess post-LT clinical outcomes.

Results: Among 811 LT patients, 766 underwent stress testing (94\%), and 559 underwent CATH (69\%) of whom $10 \%$ had CAD requiring $\mathrm{PCl}$. The sensitivity of stress echocardiography in detecting significant CAD was $37 \%$. Predictors of $\mathrm{PCl}$ included increasing age, male gender and personal history of $\mathrm{CAD}$ ( $\mathrm{p}<0.05$ for all). Compared to patients who had no CATH, patients who underwent CATH had higher mortality ( $p=0.07)$, and the hazard rates (HR) for mortality increased with CAD severity [normal CATH (HR: 1.35 [95\% Cl: 0.79, 2.33], $\mathrm{p}=0.298$ ); non-obstructive CAD (HR: 1.53 [95\% Cl: 0.84, 2.77], p=0.161); and significant CAD (HR: 1.96 [95\% Cl: 0.93, 4.15], $\mathrm{p}=0.080)]$. Post-LT outcomes were compared to the 2009-2010 subgroup from the previous study and showed similar 1-year overall mortality ( $8 \%$ and $6 \%, \mathrm{p}=0.48) ; 1$-year $\mathrm{MI}$ incidence $(<1 \%$ and $<1 \%, p=0.8$ ); and $\mathrm{MI}$ deaths as portion of all deaths ( $3 \%$ and $9 \%, \mathrm{p}=0.35$ ).

Conclusion: Stress echocardiography alone is not reliable in screening LT patients for CAD. Aggressive CAD screening with CATH is associated with low rate of $\mathrm{MI}$ and cardiac mortality and validates the previously published protocol when extrapolated over a larger sample and longer follow-up period.

This article is protected by copyright. All rights reserved 


\section{Background}

The prevalence of coronary artery disease (CAD) is rising among LT candidates. Approximately $25 \%$ of LT candidates with traditional coronary risk factors may have moderate CAD (stenosis $\geq 50 \%$ ) even while asymptomatic, and those with severe CAD have increased cardiac mortality (1). Therefore, aggressive pre-LT ischemic evaluation is necessary to assess cardiac function and identify clinically significant cardiovascular disease. Current pre-LT guidelines endorse initial assessment with electrocardiogram (EKG) and non-invasive stress testing $(2,3)$. The 2012 American Heart Association/American College of Cardiology Foundation Scientific Statement for Cardiac Disease Evaluation and Management among Kidney and Liver Transplant Candidates recommend screening with non-invasive modalities in patients with 3 or more cardiac risk factors, regardless of functional status (3). The American Association for the Study of Liver Diseases Practice Guideline was updated in 2013 to recommend stress echocardiogram (SE), whether exercise or pharmacologic, as the initial cardiovascular screening tool in all LT candidates (2).

Despite these recommendations, there is a large degree of variation between clinical practice guidelines and transplant center practice patterns with regards to who should be screened for CAD and which screening modality should be used $(4,5)$. Moreover, the clinical utility of screening asymptomatic transplant candidates remains unclear. Large randomized controlled trials for non-transplant patients do not recommend screening and revascularization of asymptomatic patients preoperatively, although these trials might not be applicable to the transplant population, where asymptomatic disease is prevalent (3). Moreover, LT candidates are at risk of hemodynamic instability due to organ dysfunction that extends beyond the cardiac system (6). Risk stratification of LT candidates remains challenging as data on cardiovascular mortality post-transplantation are based on incremental knowledge from observational studies; there are no randomized controlled trials that compare different screening modalities. Moreover, Framingham's score and traditional scores do not accurately predict cardiovascular risk score in the preoperative transplant patients (7). In context of the aforementioned, further analysis of specific risk factor combinations with respect to outcomes would allow for more selective use of cardiac evaluation, especially given that risk stratification may be a better predictive tool than stress testing in the transplant population (8).

This article is protected by copyright. All rights reserved 
An analysis of 1221 LT patients at Indiana University Hospital found significant reduction in 1-year all-cause mortality, and in the incidence of MI post-transplant, with increased frequency of CATH and percutaneous coronary intervention (PCI) over 3 time periods between 2000-2010 (9). Period A (2000-2004) included 527 patients who were initially referred to general cardiology, all of them had a 2-dimensional echocardiogram, and CATH was at the discretion of the consulting cardiologist. Period B (2005-2008) included 520 patients who were evaluated by select cardiologists, and these patients underwent SE with or without CATH. Period C (2009-2010) included 174 patients who were evaluated by a single cardiologist. Since 2009, our center has adopted a policy of cardiac evaluation by a single cardiologist including stress testing and CATH. CATH was indicated based on risk factors even in the presence of negative stress test findings. These risk factors included age, smoking history, diabetes, hypertension requiring medications, history of CAD, family history of $\mathrm{CAD}$, and obesity. A lower threshold for $\mathrm{PCl}$ was adopted at $\geq 50 \%$ stenosis in a major vessel (left anterior descending artery or right coronary artery) or critical disease, defined as stenosis $\geq 70 \%$ in at least moderatesized branch vessels.

This study is a follow-up of the previous analysis and will help in further understanding cardiovascular disease in the LT population. The objective of this study is twofold. First, it builds on the previous study by further analyzing the role of universal stress testing and use of CATH based on predefined risk factors over a longer duration (2010-2016) and in a larger population. The efficacy of stress testing alone to identify CAD in the liver failure population will be assessed. Second, this study reports the long-term outcomes of an aggressive CAD screening protocol with CATH based on risk factors, and a lower threshold for coronary intervention.

One-year all-cause mortality, 1-year MI incidence, and MI deaths are reported, as well as long-term survival.

\section{Methods}

\section{Data Collection}

All patients undergoing LT at a single center between 2010 and 2016 were evaluated by a single cardiologist. The record of each of these patients was reviewed individually and collected data included: demographics (date of transplant, age at transplant, gender), etiology of cirrhosis, number of grafts (if more than one),

This article is protected by copyright. All rights reserved 
ejection fraction, CATH status (if patient underwent CATH; degree of stenosis, whether there was an intervention or not, and immediate complications), initial stress testing status and the associated result in case of SE (normal test, abnormal echocardiogram component, abnormal EKG component but normal echocardiogram component, non-diagnostic test) or nuclear test (normal or abnormal). Data related to the following cardiovascular risk factors were also analyzed: body mass index, diabetes mellitus, hypertension requiring medications, tobacco use (never user, current user at the time of evaluation, former user, and number of tobacco pack-years if there was a smoking history), personal history of CAD, and family history of CAD (negative, immediate, or distant family history). Collection of pre- and post-CATH laboratory values can be found in Supplement 1. Data were stored and updated on an online secure password-protected accesscontrolled portal. Only personnel with approval from our Institutional Review Board and who had Indiana University credentials were given access to the database.

\section{Definitions: CATH Results}

CATH results were defined as negative (no intervention) or positive (CAD $\geq 50 \%$ stenosis in a major vessel or $\geq 70 \%$ stenosis in at least a moderate-sized branch vessel requiring intervention with $\mathrm{PCl}+/$ - balloon angioplasty). Degree of stenosis was classified into three categories: normal coronaries, non-obstructive CAD ( $<50 \%$ stenosis; or $\geq 50 \%$ stenosis but not in a major vessel and not requiring intervention; or revascularized CAD; or luminal irregularities; or minor calcifications), or significant CAD ( $\geq 50 \%$ stenosis in a major vessel or $\geq 70 \%$ stenosis in at least a moderate-sized branch vessel warranting intervention).

\section{Definitions: SE Results}

SE results were defined as negative, positive, or non-diagnostic. A test was deemed negative if there were no wall motion abnormalities (WMA) with stress, no EKG changes, and no chest pain; or the SE component was normal with baseline EKG abnormalities or equivocal EKG component. A positive stress test had WMA (new or worsening with stress) +/- EKG changes +/- chest pain; or positive EKG changes per criteria without WMA (10). A stress test was considered non-diagnostic if it had equivocal findings; or $85 \%$ of maximum predicted heart rate (220-age) was not achieved; or the test was terminated due to fatigue, hypotension, hypertension, arrhythmia, or dyspnea without chest pain.

This article is protected by copyright. All rights reserved 


\section{Our CATH Protocol}

Femoral approach was used in all cases along with a combined fluoroscopic and Doppler ultrasound technique for access. Further details can be found in Supplement 2. Drug-eluting stents were routinely used since 2009 with at least 3 months of dual antiplatelet therapy, except for two patients who received at least 6-8 weeks of therapy due to the need for urgent LT. Dual antiplatelet therapy was generally restarted post-LT to continue for a total of 1 year post-PCI.

\section{Postoperative MI and Cardiac Mortality}

LT outcomes and deaths were followed and recorded by the Department of Surgery staff members. To identify 1-year cardiac mortality, the record of each patient who received LT during 2010-2016 and died was reviewed individually. The incidence of postoperative MI within 1 year after transplant date was investigated using International Classification of Diseases Ninth Revision Clinical Modification (ICD-9-CM) diagnosis codes, ICD-10-CM diagnosis codes, as well as troponin values. Troponin value of $0.03 \mathrm{ng} / \mathrm{ml}$ was used as the upper limit of normal which meets the $99^{\text {th }}$ percentile for normal range troponin values. Obtained values were filtered according to two times the upper limit of normal $(>0.06 \mathrm{ng} / \mathrm{ml})$. A total of 125 patients met the criteria, and their charts were reviewed individually. MI was defined as a troponin value more than two times the upper limit of normal with supporting evidence of EKG changes and clinical presentation.

\section{Statistical Analysis}

We used frequency distribution to describe the proportion of patients undergoing cardiac stress testing and CATH in terms of factors such as patient demographics, cardiac risk factors, Model for End-stage Liver Disease score, and graft number. Bivariate analysis using Chi-square and Fisher's exact tests, as appropriate, were conducted to examine the relationship between the aforementioned factors and results from cardiac stress testing or CATH. Unadjusted Kaplan-Meier analysis and age-adjusted Cox proportional hazards models were used to perform the survival analysis post-LT. The log-rank test was used to compare differences in survival across CATH groups. All hypotheses were tested at 0.05 level of significance and the data analysis was done in

This article is protected by copyright. All rights reserved 
Stata version 14 (StataCorp, College Station, TX, USA). Use of center data for retrospective analysis has been reviewed and approved by the Indiana University Institutional Review Board. The study protocol for this research conformed to the Declaration of Helsinki.

\section{Results}

\section{Demographics}

Data for a total of 811 LT patients were included in this analysis. The cohort's median Model for End-stage Liver Disease score was 22, age 57 years, body mass index $28 \mathrm{~kg} / \mathrm{m}^{2}$, with $67 \%$ males, and $89 \%$ identified as Caucasians (Table 1). Regarding common cardiac risk factors, 30\% were diabetic, 39\% with hypertension, $50 \%$ with any history of tobacco use, $7 \%$ had a personal history of CAD and $37 \%$ with immediate family history of CAD. The most common etiologies for cirrhosis were hepatitis C (30\%), followed by alcoholic liver disease (22\%), and non-alcoholic steatohepatitis (20\%). Of note, many patients had more than one factor contributing to their liver disease. Other less common cirrhosis etiologies are listed in Supplemental Table 1.

\section{Stress Testing Results}

There were 811 patients who underwent LT during the study period, of whom 766 had stress testing (94\%)

(Figure 1, Table 2). Notably, this refers to an initial stress test prior to CATH, if CATH was done. For example, 8 patients already had prior CATH at the time of evaluation when a subsequent stress test was obtained; these were counted among patients who did not undergo initial stress testing. SE was normal in 613 (80\%) patients. SE was abnormal in $63(8 \%)$ patients, of whom 37 (59\%) patients had WMA and 26 (41\%) patients had EKG changes but normal SE component. Non-diagnostic SE were reported in 66 (9\%) patients. Significant differences $(p \leq 0.05)$ between SE result categories were found in diabetes mellitus and personal history of

CAD (Table 2). Nuclear stress testing was performed in 24 (3\%) patients, 21 (88\%) of which were normal and 3 $(13 \%)$ of which were abnormal.

\section{CATH Results}

This article is protected by copyright. All rights reserved 
Total number of patients who had CATH was 559 (69\%) patients (Table 3). Coronary arteries were found to be normal in 314 (56\%) patients, non-obstructive CAD was found in 190 (34\%) patients, and significant or obstructive CAD requiring intervention was found in 55 (10\%) patients. Among the 55 patients who underwent CATH with $\mathrm{PCl}, 29$ (53\%) had PCl to the left anterior descending artery, $14(25 \%)$ to the right coronary artery, $8(15 \%)$ to the left circumflex artery, $3(5 \%)$ to the posterior descending artery, 7 (13\%) to a diagonal branch, and $6(11 \%)$ to a marginal branch. Sixteen patients $(29 \%)$ had PCl to two or more coronary arteries and/or branches. Significant differences $(p \leq 0.05)$ between the normal coronaries, non-obstructive $C A D$, and significant CAD groups were found in age, gender, hypertension, diabetes mellitus, and personal history of CAD (Table 3). Characteristics of patients who had positive CATH and negative CATH were compared (Figure 2).

Immediate CATH-related complications were seen in 6 (1\%) patients; 3 with positive CATH, and 3 with negative CATH (Table 3). These included dissection of left iliac artery, dissection of left circumflex and obtuse marginal arteries treated with stents, allergic reaction to platelets treated with an antihistamine agent and steroids, minor groin hematoma (2 patients), and minor dissection of right external iliac artery that was treated conservatively (no luminal obstruction; no vascular occlusion device used).

\section{SE as a Screening Tool; Pre-CATH Stress Testing}

The number of patients who underwent stress testing followed by CATH was 534 (66\%), of these 515 (96\%) patients had SE testing and 19 (4\%) patients had nuclear stress testing (Figure 1). Of the patients who had SE, 63 (12\%) were positive, 404 (78\%) were negative, and 48 (9\%) were equivocal. Of note, 1 patient had positive CATH but initial stress testing was deferred. Of the patients who had nuclear testing, 3 (16\%) had a positive test ( 1 patient had positive CATH) and $16(84 \%)$ had a negative test ( 4 patients had positive CATH). Of the 48 patients who had equivocal SE, $8(16 \%)$ patients had a positive CATH.

The number of patients who had a normal initial stress test not followed by CATH was 214 patients (28\%), whereas 420 were followed by CATH (55\%) (404 SE and 16 nuclear stress tests) (Figure 1). CATH was normal

This article is protected by copyright. All rights reserved 
in $238(57 \%)$ of these patients, showed non-obstructive disease in 152 (36\%) patients, and 30 (7\%) patients had significant CAD and received intervention. The sensitivity of SE in detecting significant CAD requiring intervention was found to be $37 \%$ (Table 4). In other words, $63 \%$ of patients who received coronary intervention had a negative screening SE.

\section{Pre- and Post-CATH Laboratory Values, Transfusions, and Acute Kidney Injury}

The mean laboratory values were obtained for all 559 patients who underwent CATH within 1 day prior to CATH. Mean hemoglobin was $11.4 \pm 2.0 \mathrm{~g} / \mathrm{dL}$, mean INR $1.5 \pm 0.4$, mean platelet count $89.9 \pm 60.7 \times 10^{9} / \mathrm{L}$, and mean creatinine $1.2 \pm 1.1 \mathrm{mg} / \mathrm{dL}$. No major bleeding events were recorded while minor bleeding events occurred in 14 patients (2.5\%). A total of 10 patients (1.8\%) received packed red blood cell transfusions preCATH and 12 patients (2.1\%) post-CATH; 78 patients (14.0\%) received platelet transfusions pre-CATH and 30 patients (5.3\%) post-CATH; 183 patients $(2.3 \%)$ received fresh frozen plasma and/or prothrombin complex concentrate pre-CATH and 82 patients (14.7\%) post-CATH. Acute kidney injury was present in 24 patients (4.3\%) up to 7 days post-CATH. Resolution of acute kidney injury occurred prior to discharge in 22 of the 24 patients, one of whom required temporary renal replacement therapy. The remaining 2 patients with no resolution of acute kidney injury were followed up by the outpatient nephrology service. One patient required intermittent hemodialysis with complete recovery while the other was diagnosed with hepatorenal syndrome and later underwent renal transplantation.

\section{Cumulative Survival and Postoperative Cardiovascular Events}

The mean follow-up period was 55.9 months with a standard deviation of 29.1 months, while the median was 52.7 months with a range of (0-109.1) months. Unadjusted Kaplan-Meier plot from 7-year cumulative survival analysis was used to compare patients who had no pre-transplant CATH, had normal coronaries, nonobstructive $C A D$, and significant CAD requiring intervention (Figure 3). Over time, the likelihood of surviving was lowest for those with severe CAD requiring intervention. The log rank test indicated that there were more estimated deaths in the CATH groups (normal, non-obstructive, severe) compared to the group with no indication for CATH (reference group), though not statistically significant ( $p=0.07)$. In the age-adjusted Cox proportional hazards model, the hazard rates (HR) of mortality increased with the severity of CAD compared

This article is protected by copyright. All rights reserved 
to those with no indication for CATH [CATH normal (HR: 1.35 [95\% Cl: 0.79, 2.33], $p=0.298$ ); non-obstructive CAD (HR: 1.53 [95\% Cl: 0.84, 2.77], p=0.161); severe CAD requiring intervention (HR: 1.96 [95\% Cl: 0.93, 4.15], $p=0.080)]$.

There were 64 total deaths at 1 year post-LT. There were $6 \mathrm{Ml}$ events at 1 year ( 3 in the normal CATH group, 2 in the non-obstructive group, and 1 in the severe CAD group), of which 2 were fatal ( 1 in the normal CATH group and 1 in the non-obstructive group). In comparison, there were 11 deaths and 1 fatal Ml event at 1 year in the 2009-2010 cohort. Hence, post-LT 1-year MI mortality and overall 1-year mortality in this study were comparable to the $2009-2010$ cohort in the previous study who were managed using the same protocol (3\% vs. $9 \%$ (of deaths) $[p=0.35]$ and $8 \%$ vs. $6 \%$ (of all patients) [p=0.48], respectively) (Figure 4).

The average timing for the incidence of cardiovascular event, indicated by elevated troponin, was 10 days post-transplant with a median of 4 days. The average peak troponin was $0.54 \mathrm{ng} / \mathrm{ml}$ and the median was 0.24 $\mathrm{ng} / \mathrm{ml}$. Cardiology team was consulted on 25 patients based on clinical symptoms, EKG changes, or increasing troponin values. Troponin was found to be elevated in setting of acute coronary syndrome, arrhythmias (atrial fibrillation, atrial flutter, and bradycardia with pauses), angiographically-proven coronary spasm, pericarditis, demand ischemia and stress cardiomyopathy in context of acute illness or profound anemia or shock requiring the use of vasopressors.

\section{Discussion}

Historically, it was thought that patients with end-stage liver disease are at lower risk of developing CAD as a result of hemodynamic and hormonal imbalances, as well as abnormal hepatic synthetic function seen in cirrhosis $(11,12)$. However, recent studies have shown that the prevalence of CAD in LT patients is equal to or greater than the general population $(13,14)$. Carey et al. evaluated 37 patients over age 50 awaiting LT with coronary angiography. Moderate CAD was defined as $30-70 \%$ stenosis, while severe CAD was defined as $\geq 70 \%$ stenosis, and the overall frequency of severe CAD was found to be $16 \%(15)$. Patients without risk factors were found to have significantly less CAD regardless of the type of liver disease, and diabetes was the most

This article is protected by copyright. All rights reserved 
important risk factor for moderate or severe CAD. Another study evaluated 161 patients over age 45 with angiography as part of LT evaluation and found that the prevalence of moderate (50\% to $70 \%)$ to severe (>70\%) CAD was $26 \%$ (14). The patients were more likely to be men and have hypertension or diabetes mellitus. Results from the present study show that significant CAD ( $\geq 50 \%$ stenosis in a major vessel warranting intervention) occurred in $10 \%$ of patients who underwent CATH or $7 \%$ of the total study population of 811 patients. Presence of CAD in this study was significantly associated with increasing age, male gender, personal history of CAD, diabetes mellitus and hypertension. These were all factors included in the risk factor screening adopted by our center in 2009, with the addition of smoking history, family history of CAD, and obesity. Results from this study suggest that these factors constitute an appropriate list for screening in this population.

Pre-transplant echocardiographic findings have yielded conflicting results with regards to predicting posttransplant morbidity and mortality (16-18). When stress tests were used as primary screening tools, they had low sensitivity and positive predictive value for asymptomatic patients, rendering them ineffective tools for this purpose $(1,19-21)$. In addition, higher MI rates were noted when dobutamine SE was the primary screening test in our center (9). The sensitivity and specificity of SE in detecting significant angiographicallyproven CAD were calculated in our study as $37 \%$ and $89 \%$, respectively. In comparison, Harinstein et al. found the sensitivity to be $13 \%$, with comparable specificity of $85 \%$ in a total of 105 patients (22). These results suggest that $\mathrm{SE}$ is a poor screening test for CAD in LT candidates. The low sensitivity, or high false-negative event rate, may be due to inadequate response of beta-receptors to sympathetic stimulation in cirrhotic patients and/or concomitant use of beta-blockers for variceal bleeding prophylaxis, reducing the ability to reach target heart rates and subsequent induction of WMA with adequate stress levels (6).

Coronary computed tomography angiography (CCTA) may be an acceptable alternative to CATH in patients with low risk of CAD (1). However, its quality is affected by patient's clinical and physical status and it has poor positive predictive value of detecting significant CAD requiring revascularization (1, 23-25). Further studies are needed to evaluate the role of CCTA in detecting CAD in LT population, since to this date, there have been no reports comparing CCTA to CATH and the current studies included relatively small sample sizes. It is important to note that patients with renal dysfunction were excluded in these studies and the contrast

This article is protected by copyright. All rights reserved 
volume used was not reported. The amount of contrast used for CCTA is center-dependent; a typical CCTA requires $90-120 \mathrm{~mL}$ of iodine contrast (26). Therefore, it might not be a good alternative for patients with renal dysfunction in whom a diagnostic CATH may be performed with a lower amount of contrast.

Coronary angiography has been increasingly utilized to screen for CAD among LT candidates. However, this practice is not currently endorsed by American Heart Association/American College of Cardiology Foundation or American Association for the Study of Liver Diseases guidelines and remains center-specific. Multiple studies have analyzed the effect of revascularization on post-transplant survival. A small study of 47 LT patients who underwent CATH as part of pre-transplant workup found that the presence of multivessel CAD was associated with decreased survival following transplantation, even in the absence of severe coronary artery stenosis, suggesting that coronary angiography before transplantation may have a prognostic value. Notably, only 2 of these patients underwent revascularization (27). Among 630 patients undergoing pre-LT CATH in a multicenter cohort study over a 12-year period, there was no significant difference in 1-year survival between patients with obstructive CAD ( $\geq 50 \%$ stenosis) of whom $53 \%$ were revascularized, and those without obstructive CAD (28). Satapathy et al. reported on 87 LT recipients and found that survival in patients who underwent $\mathrm{CATH}$, with revascularization when indicated, was comparable to those presumed not to have CAD based on non-invasive testing (29). In our study, patients who had an indication for CATH had lower 7-year survival as compared to those who did not undergo CATH (reference group), regardless of the CATH results. This indicates that the presence of certain risk factors could be an important determinant of longterm survival. It is important to note that mortality in this study did increase with the severity of CAD, while there was no significant difference in survival between the normal CATH, non-obstructive CAD, and obstructive CAD (revascularized) groups compared to the reference group $(p=0.30, p=0.16$, and $p=0.08$, respectively). This finding is likely related to the small sample size in these subgroups.

The rate of $\mathrm{MI}$ in our center is lower than what was previously reported in the literature. The $\mathrm{MI}$ rate during a median follow-up of 4 years was $2.8 \%$ in a German cohort of 352 LT patients that were screened per published guidelines (30). It is also lower than what was previously published in a review paper by Ali et al. comparing eight studies that used different screening modalities (31). Moreover, patients in the significant CAD group of our study only had 1 non-fatal MI. In addition, their survival at 7 years was less than $10 \%$ lower

This article is protected by copyright. All rights reserved 
than patients with no CAD. Therefore, patients with significant CAD requiring intervention have reasonable long-term outcomes and should not be excluded if they are otherwise good candidates for LT.

Patients with end-stage liver disease are more prone to CATH-related complications due to thrombocytopenia, anemia, coagulopathy, and kidney disease. Hence, they are at a higher risk of major bleeding, are more likely to require transfusions after $\mathrm{CATH}$, and are at a higher risk of vascular complications such as pseudoaneurysms (32). In our study, 6 (1\%) patients experienced immediate CATH-related complications. All cases were done using the femoral approach. Recently, a consensus published by the American Transplant Society recommended a radial approach in patients undergoing LT evaluation to improve hemostasis and reduce periprocedural complications (1). However, it is worth mentioning that our study (1/2010-12/2016) took place prior to the published consensus in $1 / 2018$. In addition, the aforementioned recommendation favoring radial approach was based on 2 retrospectives studies. The first study by Huded et al. compared the rate of vascular and bleeding complications in a sample of 1071 patients (10\% LT candidates, 90\% non-LT candidates) undergoing CATH by radial approach (33). The study showed no difference in the rate of complications between the two groups. However, it does not directly compare radial and femoral approaches. Similarly, in the second study by Jacobs et al. radial CATH was performed in 82 patients with end-stage liver disease (34). Authors found this approach to be safe in LT candidates but again did not directly compare outcomes with the femoral approach. The RIVAL trial was the first large trial comparing radial versus femoral access for $\mathrm{PCl}$ in patients with acute coronary syndrome (35). There was no statistical difference in the primary outcome of a composite of death, $\mathrm{MI}$, stroke or major bleeding between the two arms of the trial. There were significantly fewer vascular complications in the radial access group with respect to hematomas and pseudoaneurysms needing closure. However, it is important to note that the rate of major vascular complications with the radial approach was not superior to the femoral approach at highvolume femoral centers. A similar observation can be seen in the MATRIX trial, the largest randomized trial comparing radial versus femoral access in acute coronary syndrome (36). The rate of net adverse clinical events were similar between the radial and femoral groups at centers using predominantly femoral access, but the rate was higher at centers using predominantly radial access. Furthermore, a recent meta-analysis of randomized controlled trials in acute coronary syndrome suggests that the reported differences between the radial versus femoral approach may have been driven by adverse events in the femoral groups rather than beneficial effects of the radial approach (37). To date, there is no study that compares the two approaches in

This article is protected by copyright. All rights reserved 
the LT population. Based on the aforementioned data, the patient population and operator's experience might be more important for outcomes than the access site. The femoral technique used in our center was performed by an experienced single operator who used combined fluoroscopic and Doppler ultrasound guidance for optimal common femoral artery access in all cases, closure devices in more than $95 \%$ of the cases to reduce bleeding complications, and took appropriate precautions with reversing coagulopathies as necessary. Access site management in the RIVAL and MATRIX trials were left to the operator's discretion; the use of ultrasound was not mandated, and only $25.6 \%$ use of closure devices was reported in the RIVAL trial. Our center's technique did not result in any major bleeding events and in a minor bleeding incidence of only $2.5 \%$. Another point is that with radial access, in addition to using vasodilating agents, $2500-5000$ units of intra-arterial heparin or up to $100 \mathrm{lU} / \mathrm{Kg}$ is used to prevent thrombus formation after the wire is inserted that may lead to radial artery occlusion (38). Heparin is not needed in the femoral approach unless $\mathrm{PCl}$ is required. This is important to consider in the LT population where the risk of bleeding is already high due to coagulopathy.

CATH can be considered a safe procedure in LT patients $(9,32)$. However, it should be acknowledged that risk stratification by using a combination of risk factors may be a valuable tool that could allow for more selective use of CATH. As above, presence of CAD in our study was significantly associated with increasing age, male gender, personal history of CAD, hypertension, and diabetes mellitus. These results support a protocol of aggressive CAD screening with CATH based on risk factors and a lower threshold for coronary intervention, as it is associated with low cardiac morbidity and mortality.

We acknowledge the limitations of a retrospective study including the availability of test results, and reliability of clinical documentation and data collection. Also, our data represents a single center's transplant population which might differ from other centers. However, this might contribute to the strength of this study in having a single CATH operator and a strict protocol for patient selection and performing CATH. The rates of $\mathrm{MI}$ and mortality are likely underestimated in this cohort due to the retrospective design and reliance on available data. Additionally, delayed complications of CATH were not surveyed. Lastly, since this study only focuses on the preoperative LT evaluation, data collection pertaining to CAD for patients who were evaluated for, but did not undergo LT, was not performed.

This article is protected by copyright. All rights reserved 


\section{Conclusion}

This study shows that SE may not be a reliable screening tool for CAD in LT patients. The reported results serve as a validation of the previously published protocol by showing comparable outcomes of low rate of $\mathrm{MI}$ and cardiac mortality with aggressive CAD screening when extrapolated over a larger sample and longer follow-up period. Therefore, patients with significant CAD requiring intervention have reasonable long-term outcomes and should not be excluded if they are otherwise good candidates for LT.

This article is protected by copyright. All rights reserved 


\section{References}

1. VanWagner LB, Harinstein ME, Runo JR, Darling C, Serper M, Hall S, Kobashigawa JA, et al. Multidisciplinary approach to cardiac and pulmonary vascular disease risk assessment in liver transplantation: An evaluation of the evidence and consensus recommendations. Am J Transplant 2018;18:30-42.

2. Martin P, DiMartini A, Feng S, Brown R, Jr., Fallon M. Evaluation for liver transplantation in adults: 2013 practice guideline by the American Association for the Study of Liver Diseases and the American Society of Transplantation. Hepatology 2014;59:1144-1165.

3. Lentine KL, Costa SP, Weir MR, Robb JF, Fleisher LA, Kasiske BL, Carithers RL, et al. Cardiac disease evaluation and management among kidney and liver transplantation candidates: a scientific statement from the American Heart Association and the American College of Cardiology Foundation: endorsed by the American Society of Transplant Surgeons, American Society of Transplantation, and National Kidney Foundation. Circulation 2012;126:617-663.

4. Pisano G, Fracanzani AL, Caccamo L, Donato MF, Fargion S. Cardiovascular risk after orthotopic liver transplantation, a review of the literature and preliminary results of a prospective study. World J Gastroenterol 2016;22:8869-8882.

5. Hogan BJ, Gonsalkorala E, Heneghan MA. Evaluation of coronary artery disease in potential liver transplant recipients. Liver Transpl 2017;23:386-395.

6. Kwon HM, Hwang GS. Cardiovascular dysfunction and liver transplantation. Korean J Anesthesiol 2018;71:85-91.

7. Neal DA, Tom BD, Luan J, Wareham NJ, Gimson AE, Delriviere LD, Byrne CD, et al. Is there disparity between risk and incidence of cardiovascular disease after liver transplant? Transplantation 2004;77:93-99. 8. De Lima JJ, Sabbaga E, Vieira ML, de Paula FJ, lanhez LE, Krieger EM, Ramires JA. Coronary angiography is the best predictor of events in renal transplant candidates compared with noninvasive testing. Hypertension 2003;42:263-268.

9. Maddur H, Bourdillon PD, Liangpunsakul S, Joseph Tector A, Fridell JA, Ghabril M, Lacerda MA, et al. Role of cardiac catheterization and percutaneous coronary intervention in the preoperative assessment and management of patients before orthotopic liver transplantation. Liver Transpl 2014;20:664-672.

10. Pellikka PA, Nagueh SF, Elhendy AA, Kuehl CA, Sawada SG, American Society of E. American Society of Echocardiography recommendations for performance, interpretation, and application of stress echocardiography. J Am Soc Echocardiogr 2007;20:1021-1041.

This article is protected by copyright. All rights reserved 
11. Fede G, Privitera G, Tomaselli T, Spadaro L, Purrello F. Cardiovascular dysfunction in patients with liver cirrhosis. Ann Gastroenterol 2015;28:31-40.

12. Plevak DJ. Stress echocardiography identifies coronary artery disease in liver transplant candidates. Liver Transpl Surg 1998;4:337-339.

13. Kalaitzakis E, Rosengren A, Skommevik T, Bjornsson E. Coronary artery disease in patients with liver cirrhosis. Dig Dis Sci 2010;55:467-475.

14. Tiukinhoy-Laing SD, Rossi JS, Bayram M, De Luca L, Gafoor S, Blei A, Flamm S, et al. Cardiac hemodynamic and coronary angiographic characteristics of patients being evaluated for liver transplantation. Am J Cardiol 2006;98:178-181.

15. Carey WD, Dumot JA, Pimentel RR, Barnes DS, Hobbs RE, Henderson JM, Vogt DP, et al. The prevalence of coronary artery disease in liver transplant candidates over age 50. Transplantation 1995;59:859-864.

16. Bushyhead D, Kirkpatrick JN, Goldberg D. Pretransplant echocardiographic parameters as markers of posttransplant outcomes in liver transplant recipients. Liver Transpl 2016;22:316-323.

17. Batra S, Machicao VI, Bynon JS, Mehta S, Tanikella R, Krowka MJ, Zacks S, et al. The impact of left ventricular hypertrophy on survival in candidates for liver transplantation. Liver Transpl 2014;20:705-712. 18. Leithead JA, Kandiah K, Steed H, Gunson BK, Steeds RP, Ferguson JW. Tricuspid regurgitation on echocardiography may not be a predictor of patient survival after liver transplantation. Am J Transplant 2014;14:2192-2193.

19. Grande-Trillo A, Sobrino-Marquez JM, Escobedo-Mesas E, Rangel-Sousa D, Lopez-Haldon JE, LageGalle E. Preoperative Cardiac Assessment of Patients Undergoing Orthotopic Liver Transplantation: Experience in One Center. Transplant Proc 2015;47:2634-2635.

20. Nicolau-Raducu R, Gitman M, Ganier D, Loss GE, Cohen AJ, Patel H, Girgrah N, et al. Adverse cardiac events after orthotopic liver transplantation: a cross-sectional study in 389 consecutive patients. Liver Transpl 2015;21:13-21.

21. Aydinalp A, Bal U, Atar I, Ertan C, Aktaş A, Yildirir A, Ozin B, et al. Value of stress myocardial perfusion scanning in diagnosis of severe coronary artery disease in liver transplantation candidates. Transplant Proc 2009;41:3757-3760.

This article is protected by copyright. All rights reserved 
22. Harinstein ME, Flaherty JD, Ansari AH, Robin J, Davidson CJ, Rossi JS, Flamm SL, et al. Predictive value of dobutamine stress echocardiography for coronary artery disease detection in liver transplant candidates. Am J Transplant 2008;8:1523-1528.

23. Keeling AN, Flaherty JD, Davarpanah AH, Ambrosy A, Farrelly CT, Harinstein ME, Flamm SL, et al. Coronary multidetector computed tomographic angiography to evaluate coronary artery disease in liver transplant candidates: methods, feasibility and initial experience. J Cardiovasc Med (Hagerstown) 2011;12:460-468.

24. Cassagneau P, Jacquier A, Giorgi R, Amabile N, Gaubert JY, Cohen F, Muller C, et al. Prognostic value of preoperative coronary computed tomography angiography in patients treated by orthotopic liver transplantation. Eur J Gastroenterol Hepatol 2012;24:558-562.

25. Kemmer N, Case J, Chandna S, Neff GW. The role of coronary calcium score in the risk assessment of liver transplant candidates. Transplant Proc 2014;46:230-233.

26. Garcia MJ, Lessick J, Hoffmann MH, Investigators CS. Accuracy of 16-row multidetector computed tomography for the assessment of coronary artery stenosis. JAMA 2006;296:403-411.

27. Yong CM, Sharma M, Ochoa V, Abnousi F, Roberts J, Bass NM, Niemann CU, et al. Multivessel coronary artery disease predicts mortality, length of stay, and pressor requirements after liver transplantation. Liver Transpl 2010;16:1242-1248.

28. Wray C, Scovotti JC, Tobis J, Niemann CU, Planinsic R, Walia A, Findlay J, et al. Liver transplantation outcome in patients with angiographically proven coronary artery disease: a multi-institutional study. Am J Transplant 2013;13:184-191.

29. Satapathy SK, Vanatta JM, Helmick RA, Flowers A, Kedia SK, Jiang Y, Ali B, et al. Outcome of Liver Transplant Recipients With Revascularized Coronary Artery Disease: A Comparative Analysis With and Without Cardiovascular Risk Factors. Transplantation 2017;101:793-803.

30. Darstein F, Hoppe-Lotichius M, Vollmar J, Weyer-Elberich V, Zimmermann A, Mittler J, Otto G, et al. Pretransplant coronary artery disease is a predictor for myocardial infarction and cardiac death after liver transplantation. Eur J Intern Med 2018;51:41-45.

31. Ali A, Bhardwaj HL, Heuman DM, Jovin IS. Coronary events in patients undergoing orthotopic liver transplantation: perioperative evaluation and management. Clin Transplant 2013;27:E207-215.

This article is protected by copyright. All rights reserved 
32. Sharma M, Yong C, Majure D, Zellner C, Roberts JP, Bass NM, Ports TA, et al. Safety of cardiac catheterization in patients with end-stage liver disease awaiting liver transplantation. Am J Cardiol 2009;103:742-746.

33. Huded CP, Blair JE, Sweis RN, Flaherty JD. Transradial cardiac catheterization in liver transplant candidates. Am J Cardiol 2014;113:1634-1638.

34. Jacobs E, Singh V, Damluji A, Shah NR, Warsch JL, Ghanta R, Martin P, et al. Safety of transradial cardiac catheterization in patients with end-stage liver disease. Catheter Cardiovasc Interv 2014;83:360-366. 35. Jolly SS, Yusuf S, Cairns J, Niemela K, Xavier D, Widimsky P, Budaj A, et al. Radial versus femoral access for coronary angiography and intervention in patients with acute coronary syndromes (RIVAL): a randomised, parallel group, multicentre trial. Lancet 2011;377:1409-1420.

36. Valgimigli M, Frigoli E, Leonardi S, Vranckx P, Rothenbuhler M, Tebaldi M, Varbella F, et al. Radial versus femoral access and bivalirudin versus unfractionated heparin in invasively managed patients with acute coronary syndrome (MATRIX): final 1-year results of a multicentre, randomised controlled trial. Lancet 2018;392:835-848.

37. Shah R, Askari R, Haji SA, Rashid A. Mortality and operator experience with vascular access for percutaneous coronary intervention in patients with acute coronary syndromes: A pairwise and network meta-analysis of randomized controlled trials. Int J Cardiol 2017;248:114-119.

38. Hahalis GN, Leopoulou M, Tsigkas G, Xanthopoulou I, Patsilinakos S, Patsourakos NG, Ziakas A, et al. Multicenter Randomized Evaluation of High Versus Standard Heparin Dose on Incident Radial Arterial Occlusion After Transradial Coronary Angiography: The SPIRIT OF ARTEMIS Study. JACC Cardiovasc Interv 2018;11:2241-2250.

This article is protected by copyright. All rights reserved 


\section{Figure Legends}

Figure 1: Consort diagram representing 811 out of 3611 candidates who underwent LT with the pre-LT testing and their corresponding results. LT=liver transplant, $\mathrm{CATH=cardiac}$ catheterization, echo=echocardiogram.

Figure 2: Cardiac risk factors of patients who had negative CATH (no intervention) compared to patients who had positive CATH (CAD $\geq 50 \%$ stenosis in a major vessel or $\geq 70 \%$ stenosis in at least a moderate-sized branch vessel requiring intervention with $\mathrm{PCl}+/$ - balloon angioplasty). $\mathrm{CATH}=$ cardiac catheterization, $\mathrm{BMI}=$ body mass index, HTN on meds=hypertension on medications, $\mathrm{Hx}$ of $\mathrm{CAD}=$ history of coronary artery disease, PY=packyears.

Figure 3: Unadjusted Kaplan-Meier plot from 7-year cumulative survival analysis for patients who had no pretransplant cardiac catheterization (CATH), had normal coronaries, non-obstructive coronary artery disease (CAD), and significant CAD requiring intervention. Over time, the likelihood of surviving was lowest for those with severe CAD requiring intervention. The log-rank test indicated that there were more estimated deaths in the catheterization groups (normal, non-obstructive, severe) compared to the group with no indication for catheterization (reference group), though not statistically significant ( $p=0.07)$. In the age-adjusted Cox proportional hazards model, the hazard rates (HR) of mortality increased with the severity of CAD compared to those with no indication for CATH [CATH normal (HR: 1.35 [95\% Cl: 0.79, 2.33], p=0.298); non-obstructive CAD (HR: 1.53 [95\% Cl: 0.84, 2.77], p=0.161); severe CAD requiring intervention (HR: 1.96 [95\% Cl: 0.93, 4.15], $\mathrm{p}=0.080)]$.

Figure 4: Comparison between our current study (2010-2016) and a time period from our previous study (2009-2010) using the same protocol. The percentage of catheterization, intervention, 1-year mortality, MI within 1 year, and 1-year MI deaths (as portion of all deaths) was comparable between the 2 cohorts.

$\mathrm{Ml}=$ myocardial infarction.

This article is protected by copyright. All rights reserved 
Table 1. Demographics for 811 patients who underwent liver transplant.

OVERALL

MELD score

20 or less

21 to 29

30 and higher

Gender

Male

Female

Race

White

Black

Other

Age (years)

Less than 30

30 to 39

40 to 49

50 to 59

60 and older

Body mass index $\left(\mathrm{kg} / \mathrm{m}^{2}\right)$

Less than 25.0

25.0 to 29.9

30.0 to 34.9

35.0 and higher

Graft number

First

Re-transplant

\section{Etiology of Cirrhosis*}

Hepatitis C

Alcohol

$\mathrm{NASH}$

PSC

Autoimmune

PBC

Cryptogenic

Other
Number (\%)

811 (100\%)

374 (46\%)

351 (43\%)

$86(11 \%)$

546 (67\%)

265 (33\%)

723 (89\%)

44 (5\%)

44 (5\%)

31 (4\%)

$39(5 \%)$

$112(14 \%)$

317 (39\%)

312 (38\%)

$218(27 \%)$

268 (33\%)

$219(27 \%)$

106 (13\%)

786 (97\%)

$25(3 \%)$

267 (30\%)

200 (22\%)

179 (20\%)

$79(9 \%)$

$35(4 \%)$

$34(4 \%)$

$22(2 \%)$

77 (9\%)

Cardiac risk factors

This article is protected by copyright. All rights reserved 


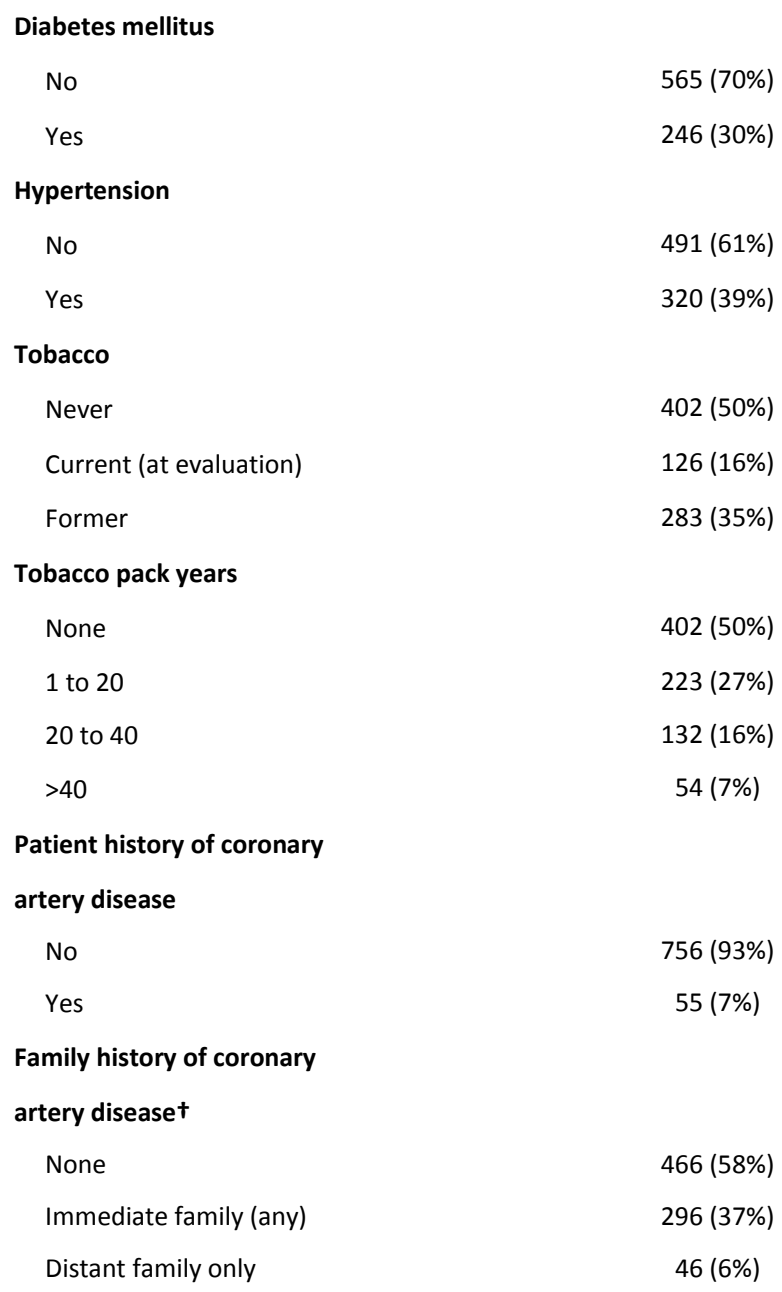

Yes

Hypertension

No

Yes

Tobacco

Never

Current (at evaluation)

Former

Tobacco pack years

None

1 to 20

20 to 40

$>40$

Patient history of coronary

artery disease

No

Yes

Family history of coronary

artery diseaset

None

Immediate family (any)

Distant family only

565 (70\%)

$246(30 \%)$

$491(61 \%)$

$320(39 \%)$

402 (50\%)

$126(16 \%)$

283 (35\%)

402 (50\%)

$223(27 \%)$

$132(16 \%)$

$54(7 \%)$

756 (93\%)

$55(7 \%)$

466 (58\%)

296 (37\%)

$46(6 \%)$

MELD: Model for End-stage Liver Disease, NASH: Non-Alcoholic SteatoHepatitis, PSC: Primary Sclerosing Cholangitis, PBC: Primary Biliary Cirrhosis. * Many patients had more than one factor contributing to their liver disease; +3 patients were adopted and did not have family history available.

This article is protected by copyright. All rights reserved 
Table 2. Results of pre-liver transplant cardiac stress testing in 766 patients who subsequently underwent liver transplant.

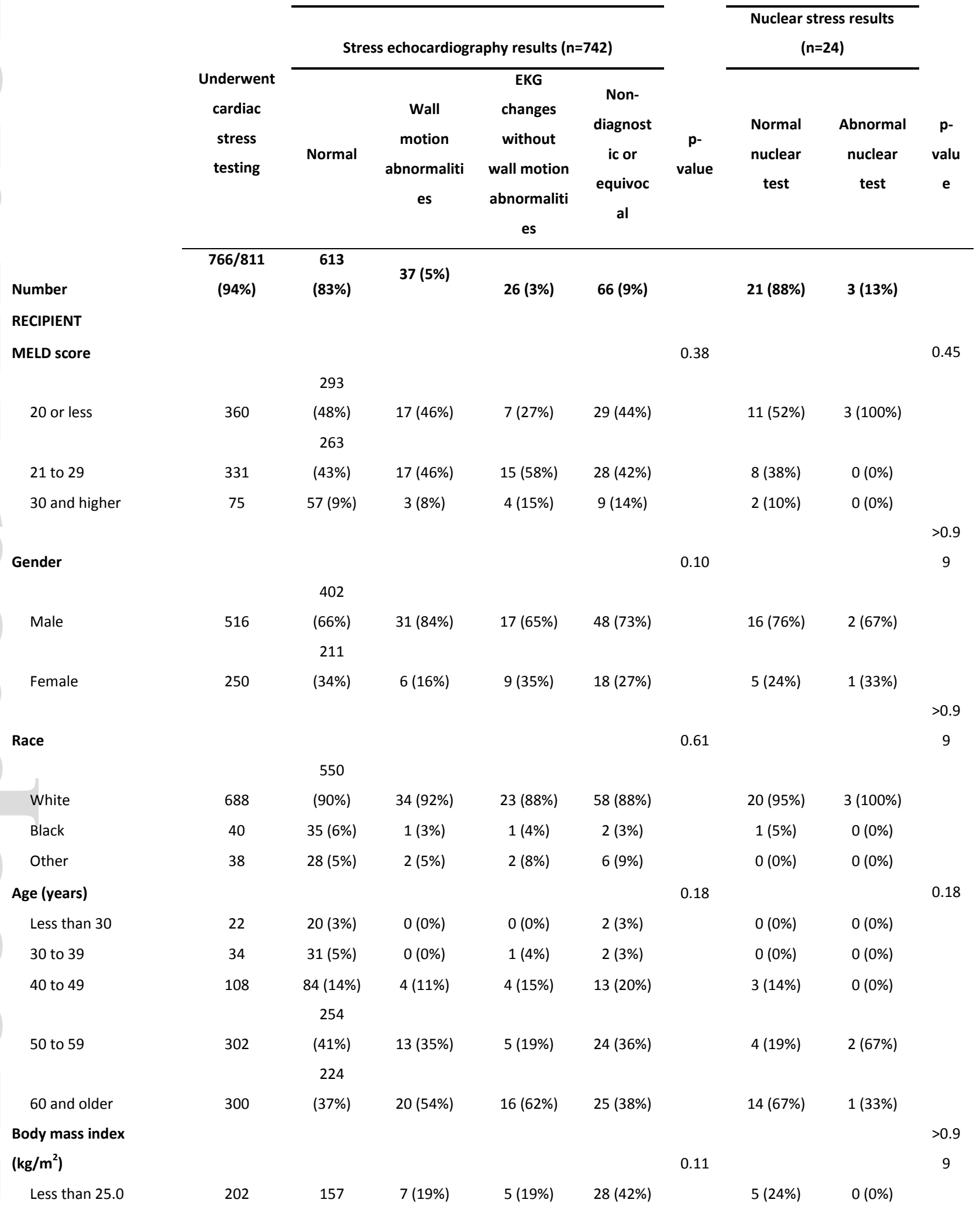

This article is protected by copyright. All rights reserved 


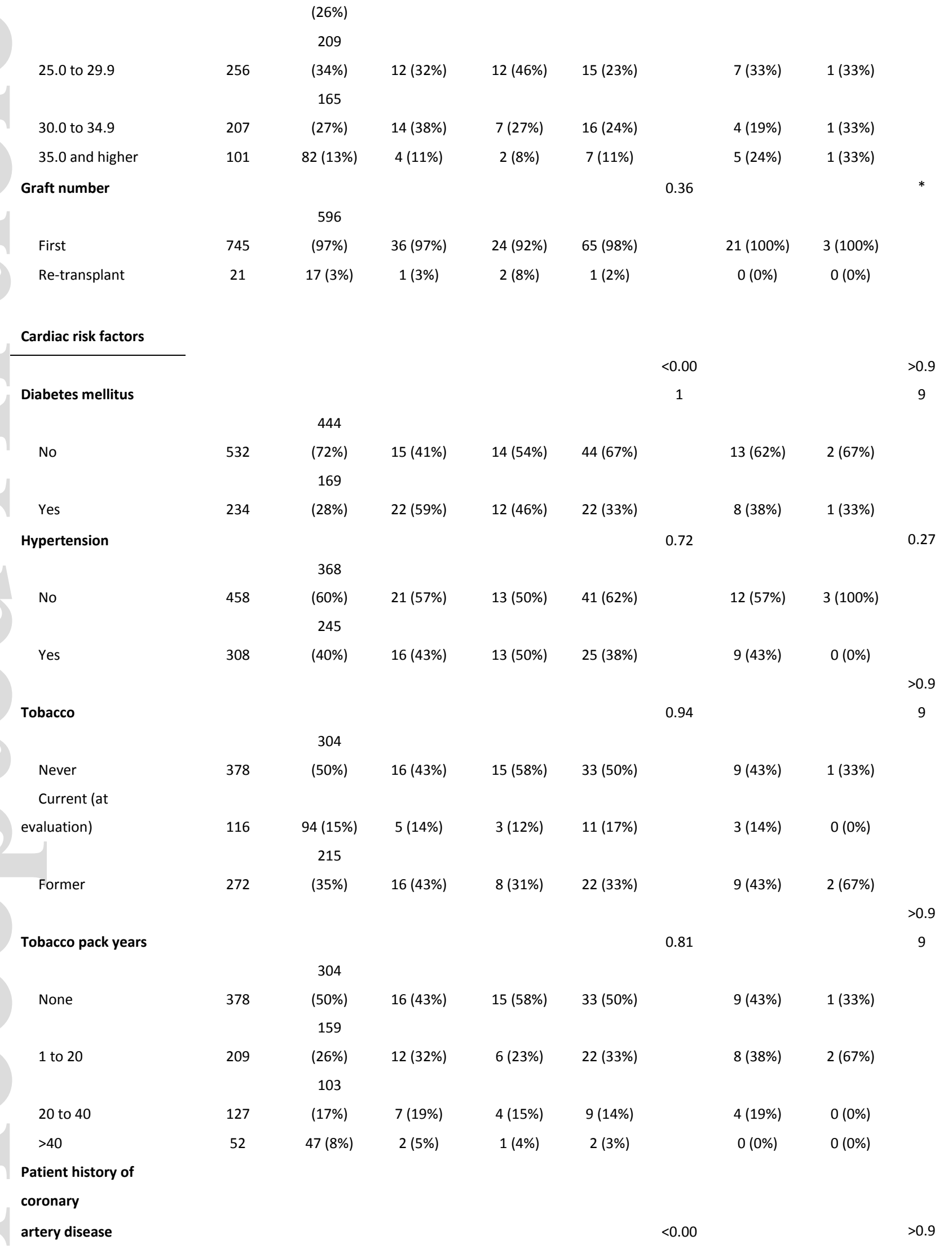

This article is protected by copyright. All rights reserved 


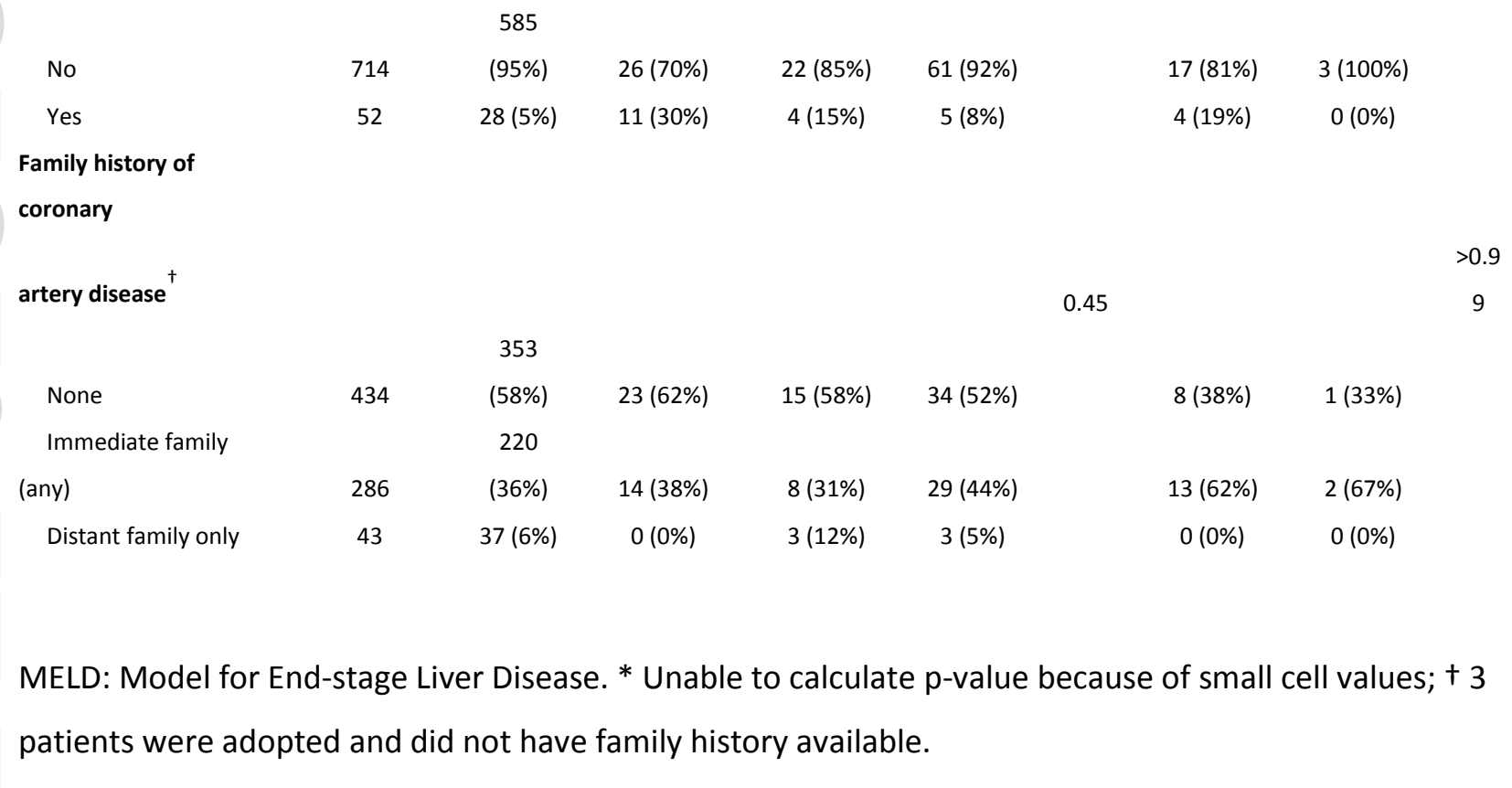

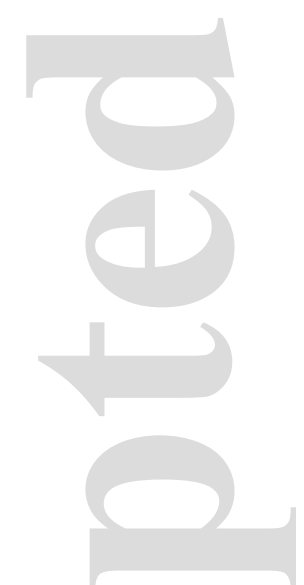

This article is protected by copyright. All rights reserved 
Table 3. Results of pre-liver transplant cardiac catheterization in 559 patients who subsequently underwent liver transplant.

\begin{tabular}{|c|c|c|c|c|c|c|c|}
\hline & \multirow{2}{*}{\multicolumn{4}{|c|}{ Cardiac catheterization results }} & \\
\hline & & & & & & & \\
\hline & $\begin{array}{c}\text { Underwent } \\
\text { cardiac } \\
\text { catheterization }\end{array}$ & $\begin{array}{c}\text { Normal or no } \\
\text { catheterization } \\
\text { indicated }\end{array}$ & $\begin{array}{c}\text { Non- } \\
\text { obstructive } \\
\text { coronary } \\
\text { artery disease }\end{array}$ & $\begin{array}{c}\text { Obstructive } \\
\text { coronary artery } \\
\text { disease requiring } \\
\text { intervention }\end{array}$ & \multirow[t]{2}{*}{$\begin{array}{c}p \text { - } \\
\text { value }\end{array}$} & $\begin{array}{c}\text { Complication } \\
\text { of } \\
\text { catheterization }\end{array}$ & \multirow[t]{2}{*}{$\begin{array}{c}\mathrm{p}- \\
\text { value }\end{array}$} \\
\hline Number & $559 / 811(69 \%)$ & $314(56 \%)$ & $190(34 \%)$ & $55(10 \%)$ & & $6(1 \%)$ & \\
\hline \multicolumn{8}{|l|}{ RECIPIENT } \\
\hline MELD score & & & & & 0.73 & & 0.48 \\
\hline 20 or less & $264(47 \%)$ & $151(48 \%)$ & $91(48 \%)$ & $22(40 \%)$ & & $2(33 \%)$ & \\
\hline 21 to 29 & 247 (44\%) & 137 (44\%) & $84(44 \%)$ & $26(47 \%)$ & & $4(67 \%)$ & \\
\hline 30 and higher & $48(9 \%)$ & $26(8 \%)$ & $15(8 \%)$ & $7(13 \%)$ & & $0(0 \%)$ & \\
\hline Gender & & & & & $<0.01$ & & 0.67 \\
\hline Male & $391(70 \%)$ & $202(64 \%)$ & $141(74 \%)$ & $48(87 \%)$ & & $5(83 \%)$ & \\
\hline Female & $168(30 \%)$ & $112(36 \%)$ & $49(26 \%)$ & $7(13 \%)$ & & $1(17 \%)$ & \\
\hline Race & & & & & 0.81 & & 0.29 \\
\hline White & $509(91 \%)$ & $284(90 \%)$ & 173 (91\%) & $52(95 \%)$ & & $5(83 \%)$ & \\
\hline Black & $26(5 \%)$ & $15(5 \%)$ & $10(5 \%)$ & $1(2 \%)$ & & $0(0 \%)$ & \\
\hline Other & $24(4 \%)$ & $15(5 \%)$ & $7(4 \%)$ & $2(4 \%)$ & & $1(17 \%)$ & \\
\hline Age (years) & & & & & $<0.001$ & & $*$ \\
\hline Less than 30 & $0(0 \%)$ & $0(0 \%)$ & $0(0 \%)$ & $0(0 \%)$ & & $0(0 \%)$ & \\
\hline 30 to 39 & $4(1 \%)$ & $3(1 \%)$ & $1(1 \%)$ & $0(0 \%)$ & & $1(17 \%)$ & \\
\hline 40 to 49 & $40(7 \%)$ & $30(10 \%)$ & $8(4 \%)$ & $2(4 \%)$ & & $0(0 \%)$ & \\
\hline 50 to 59 & $220(39 \%)$ & $145(46 \%)$ & $62(33 \%)$ & $13(24 \%)$ & & $1(17 \%)$ & \\
\hline 60 and older & 295 (53\%) & $136(43 \%)$ & $119(63 \%)$ & $40(73 \%)$ & & $4(67 \%)$ & \\
\hline Body mass index $\left(\mathrm{kg} / \mathrm{m}^{\wedge} 2\right)$ & & & & & 0.22 & & $*$ \\
\hline Less than 25.0 & $127(23 \%)$ & $74(24 \%)$ & $36(19 \%)$ & $17(31 \%)$ & & $2(33 \%)$ & \\
\hline 25.0 to 29.9 & $189(34 \%)$ & $95(30 \%)$ & 77 (41\%) & $17(31 \%)$ & & $1(17 \%)$ & \\
\hline 30.0 to 34.9 & $161(29 \%)$ & 95 (30\%) & $51(27 \%)$ & $15(27 \%)$ & & $3(50 \%)$ & \\
\hline 35.0 and higher & $82(15 \%)$ & $50(16 \%)$ & $26(14 \%)$ & $6(11 \%)$ & & $0(0 \%)$ & \\
\hline Graft number & & & & & 0.06 & & 0.74 \\
\hline First & $549(98 \%)$ & 311 (99\%) & $186(98 \%)$ & $52(95 \%)$ & & $6(100 \%)$ & \\
\hline Re-transplant & $10(2 \%)$ & $3(1 \%)$ & $4(2 \%)$ & $3(5 \%)$ & & $0(0 \%)$ & \\
\hline \multicolumn{8}{|l|}{ Cardiac risk factors } \\
\hline Diabetes mellitus & & & & & 0.05 & & $*$ \\
\hline No & $338(60 \%)$ & $204(65 \%)$ & 105 (55\%) & $29(53 \%)$ & & $3(50 \%)$ & \\
\hline Yes & 221 (40\%) & $110(35 \%)$ & $85(45 \%)$ & $26(47 \%)$ & & $3(50 \%)$ & \\
\hline Hypertension & & & & & 0.03 & & $*$ \\
\hline
\end{tabular}

This article is protected by copyright. All rights reserved 


\begin{tabular}{|c|c|c|c|c|c|c|c|}
\hline No & $305(55 \%)$ & $187(60 \%)$ & $92(48 \%)$ & $26(47 \%)$ & & $4(67 \%)$ & \\
\hline Yes & $254(45 \%)$ & $127(40 \%)$ & $98(52 \%)$ & $29(53 \%)$ & & $2(33 \%)$ & \\
\hline Tobacco & & & & & 0.97 & & $*$ \\
\hline Never & $221(40 \%)$ & $124(39 \%)$ & 75 (39\%) & $22(40 \%)$ & & $1(17 \%)$ & \\
\hline Current (at evaluation) & $107(19 \%)$ & $63(20 \%)$ & $35(18 \%)$ & $9(16 \%)$ & & $3(50 \%)$ & \\
\hline Former & $231(41 \%)$ & $127(40 \%)$ & $80(42 \%)$ & $24(44 \%)$ & & $2(33 \%)$ & \\
\hline Tobacco pack years & & & & & 1.00 & & * \\
\hline None & $221(40 \%)$ & $124(39 \%)$ & $75(39 \%)$ & $22(40 \%)$ & & $1(17 \%)$ & \\
\hline 1 to 20 & $164(29 \%)$ & $92(29 \%)$ & $57(30 \%)$ & $15(27 \%)$ & & $3(50 \%)$ & \\
\hline 20 to 40 & $123(22 \%)$ & $71(23 \%)$ & $40(21 \%)$ & $12(22 \%)$ & & $2(33 \%)$ & \\
\hline$>40$ & $51(9 \%)$ & $27(9 \%)$ & $18(9 \%)$ & $6(11 \%)$ & & $0(0 \%)$ & \\
\hline \multicolumn{8}{|l|}{ Patient history of coronary } \\
\hline artery disease & & & & & $<0.001$ & & * \\
\hline No & $506(91 \%)$ & 307 (98\%) & $164(86 \%)$ & $35(64 \%)$ & & $4(67 \%)$ & \\
\hline Yes & $53(9 \%)$ & $7(2 \%)$ & $26(14 \%)$ & $20(36 \%)$ & & $2(33 \%)$ & \\
\hline \multicolumn{8}{|l|}{ Family history of coronary } \\
\hline artery disease $^{\dagger}$ & & & & & 0.25 & & * \\
\hline None & $300(54 \%)$ & $180(57 \%)$ & $96(51 \%)$ & $24(44 \%)$ & & $3(50 \%)$ & \\
\hline Immediate family (any) & $236(42 \%)$ & $123(39 \%)$ & $84(44 \%)$ & $29(53 \%)$ & & $3(50 \%)$ & \\
\hline Distant family only & $23(4 \%)$ & $11(4 \%)$ & $10(5 \%)$ & $2(4 \%)$ & & $0(0 \%)$ & \\
\hline
\end{tabular}

MELD: Model for End-stage Liver Disease. * Unable to calculate $p$-value because of small cell values; $† 3$ patients were adopted and did not have family history available.

This article is protected by copyright. All rights reserved 
Table 4. Utility of pre-liver transplant stress echocardiography testing in predicting coronary artery disease requiring intervention.

\begin{tabular}{|c|c|c|c|c|}
\hline & & Cardiac Cath & & \\
\hline & & Positive & Negative & \\
\hline Stress & & & & \\
\hline echocardiogram & Positive & 15 & 48 & 63 \\
\hline & Negative & 26 & 378 & 404 \\
\hline & & 41 & 426 & 467 \\
\hline & Sensitivity & $15 / 41 * 100$ & & \\
\hline
\end{tabular}

This article is protected by copyright. All rights reserved 


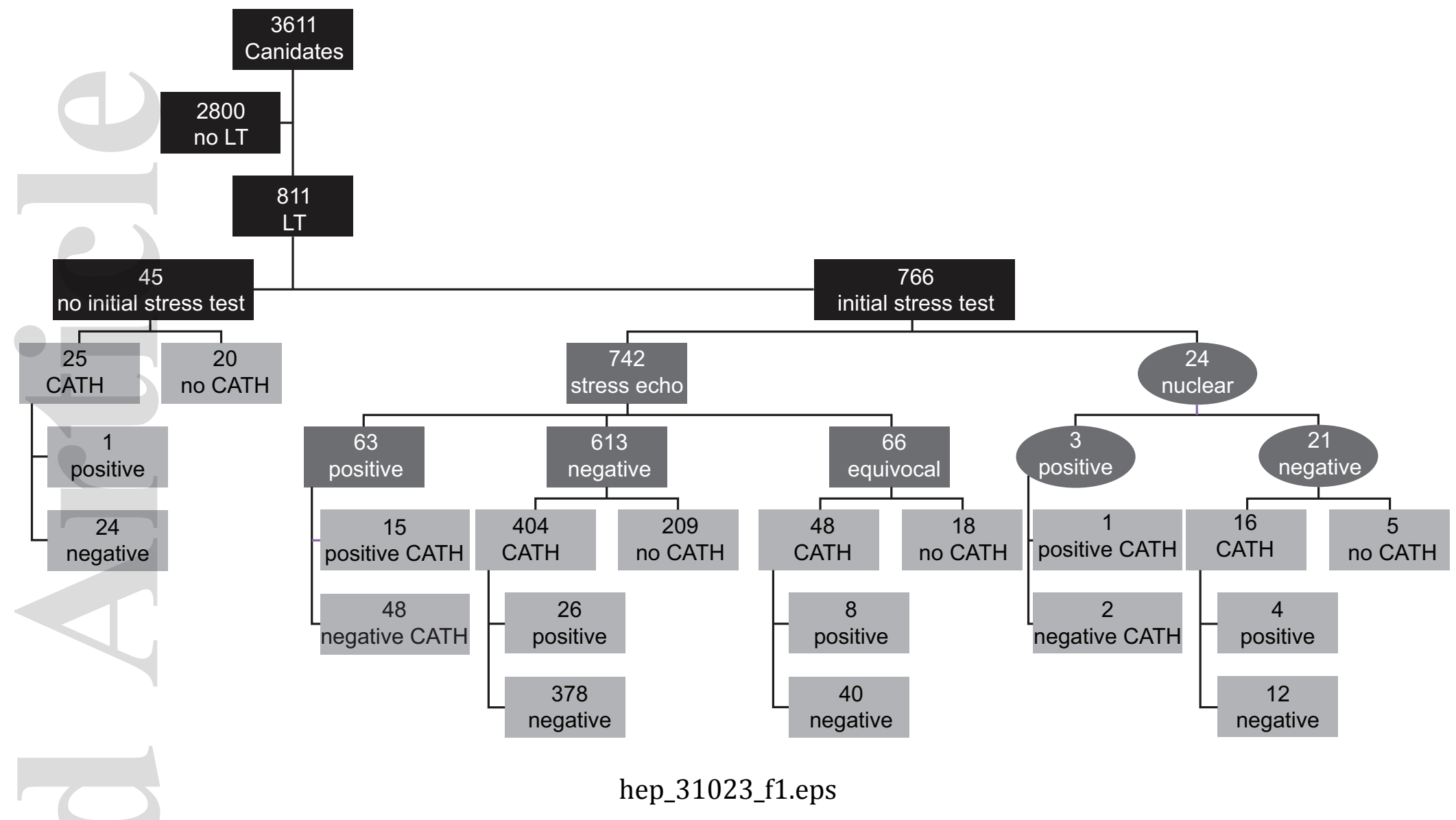

This article is protected by copyright. All rights reserved 


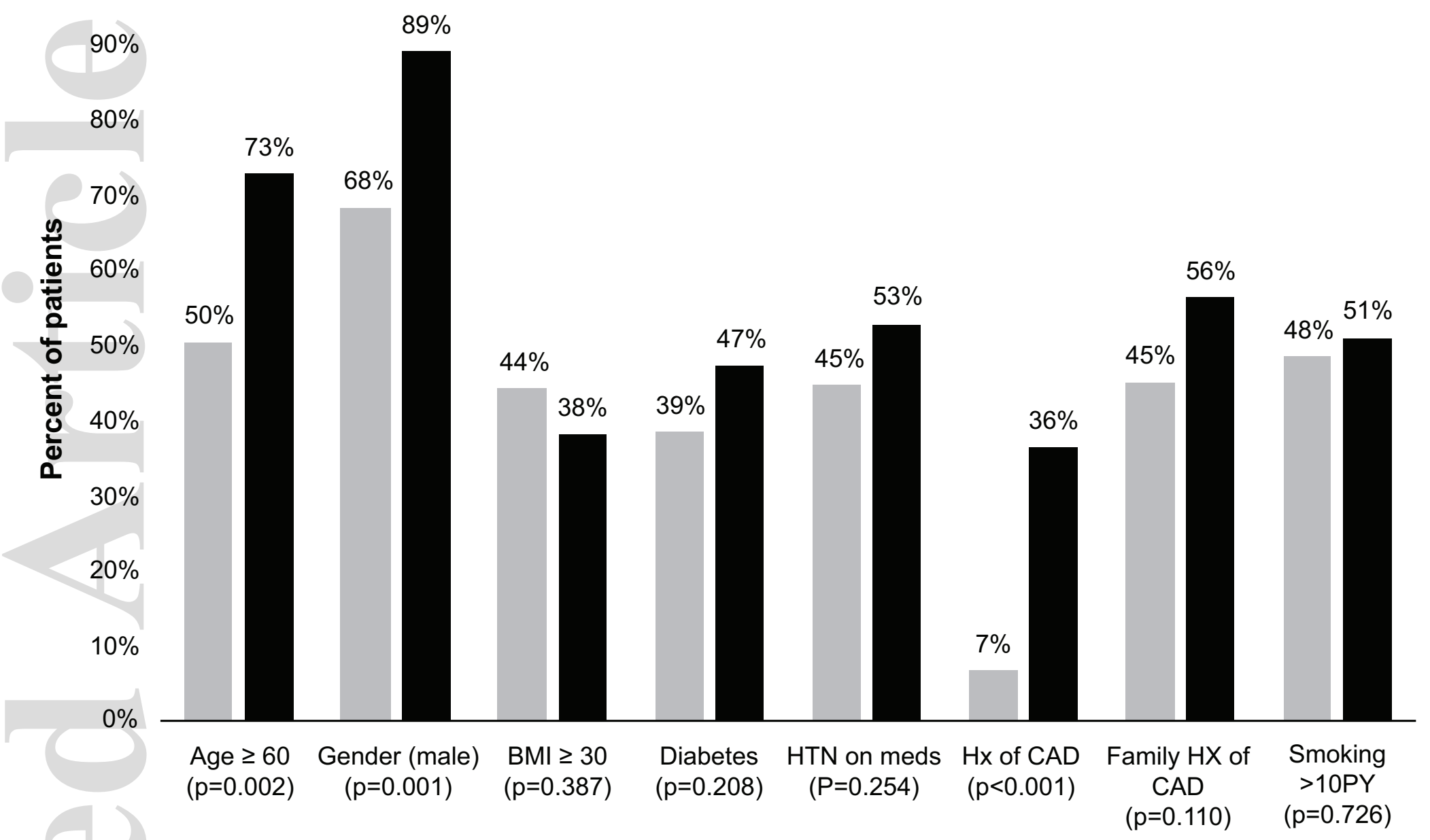

Cardiac Risk Factor

$\square$ CATH negative $\square$ CATH positive

hep_31023_f2.eps 


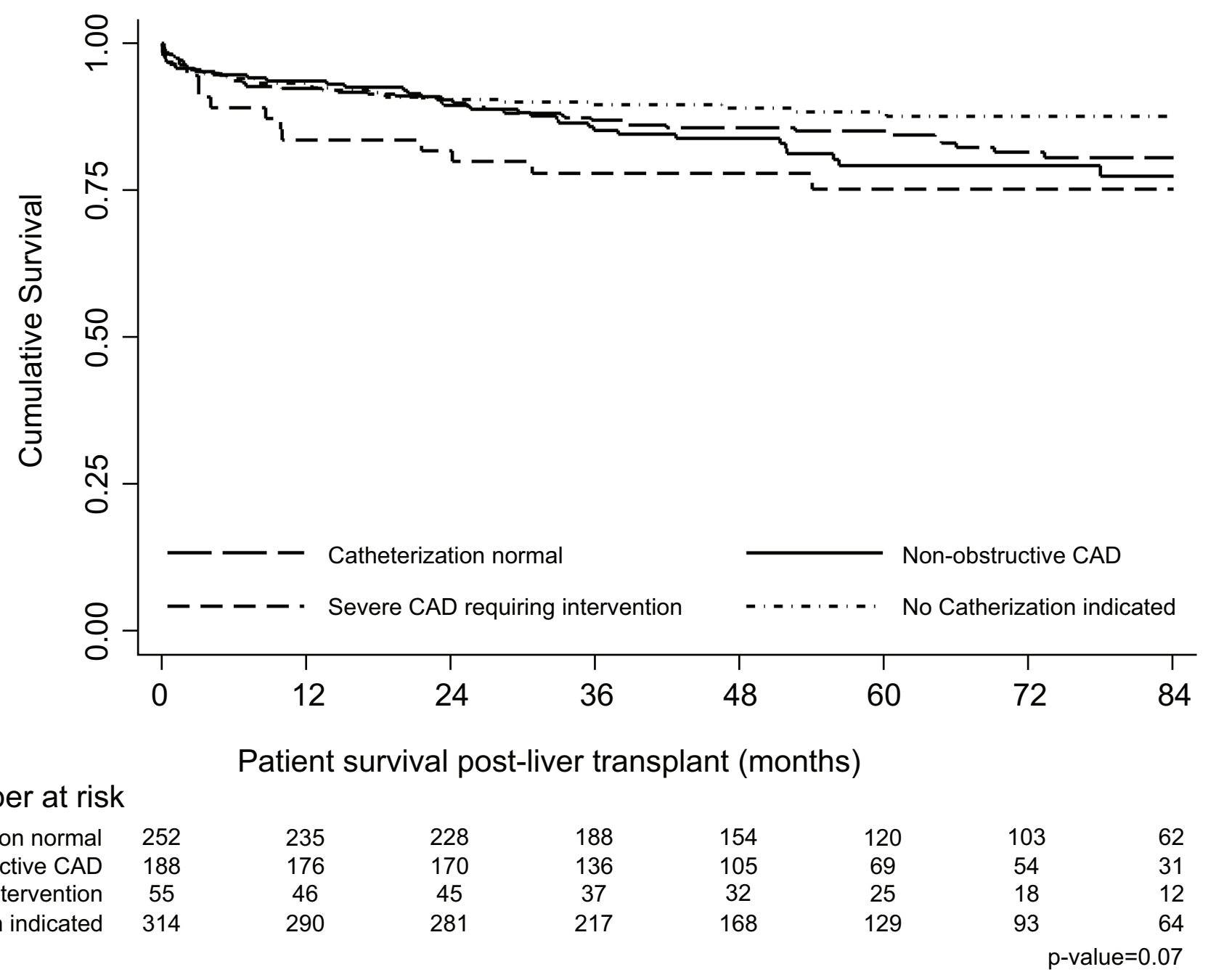

hep_31023_f3.eps 
$100 \%$

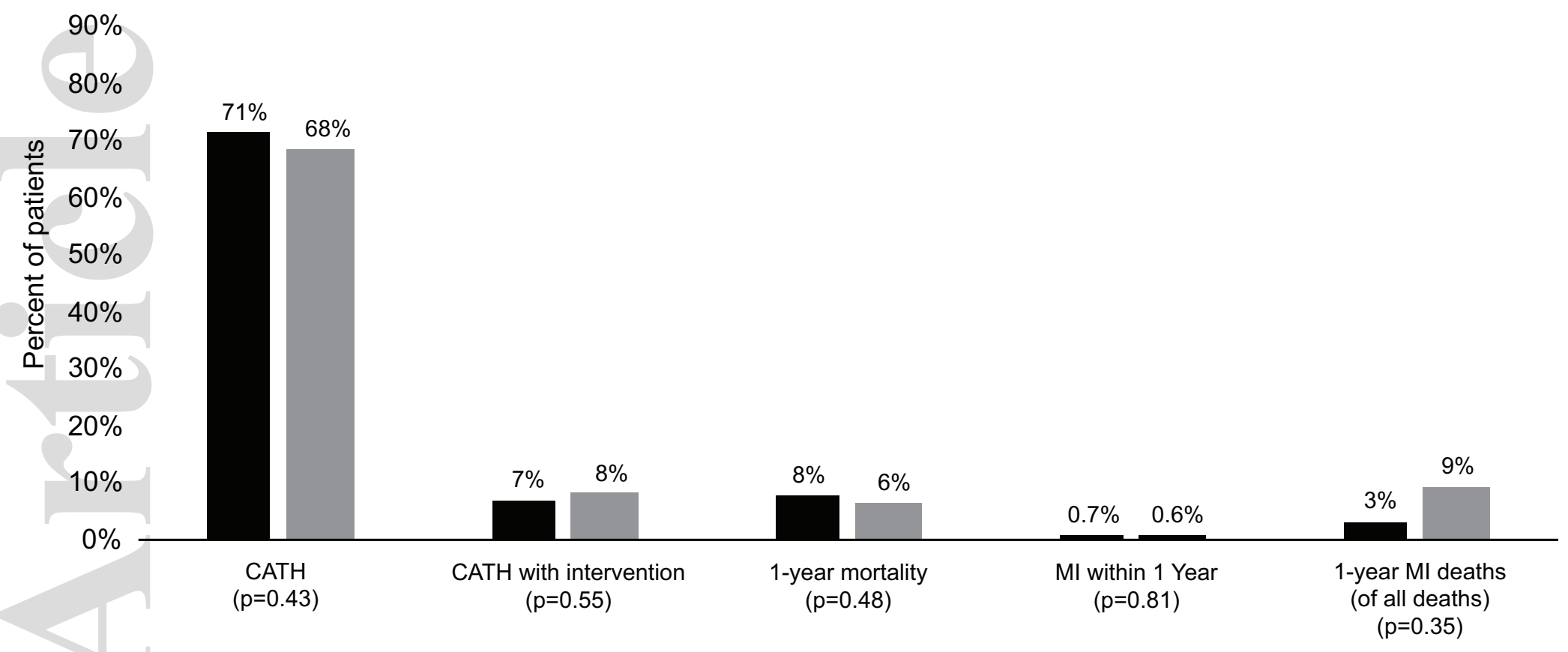

Our Study [n=811;2010-2016] Maddur Group C [n=174; 2009-2010]

hep_31023_f4.eps 